\title{
How important is dietary management in chronic kidney disease progression? A role for low protein diets
}

\author{
Gang-Jee $\mathrm{Ko}^{1}$ and Kamyar Kalantar-Zadeh ${ }^{2,3,4}$
}

\begin{abstract}
${ }^{1}$ Department of Internal Medicine, Korea University College of Medicine, Seoul, Korea; ${ }^{2}$ Harold Simmons Center for Kidney Disease Research and Epidemiology, University of California Irvine, School of Medicine, Orange, CA; ${ }^{3}$ Department of Medicine, Long Beach Veteran Affairs Health System, Long Beach, $\mathrm{CA} ;{ }^{4}$ Los Angeles Biomedical Research Institute at Harbor, University of California Los Angeles, Torrance, CA, USA
\end{abstract}

Received: April 21, 2021 Accepted: June 8, 2021

\section{Correspondence to}

Gang-Jee Ko, M.D.

Division of Nephrology,

Department of Internal

Medicine, Korea University

Guro Hospital, 148 Gurodong-ro,

Guro-gu, Seoul o8308, Korea

Tel: +82-2-2626-3039

Fax: +82-2-2626-1078

E-mail: lovesba@korea.ac.kr

https://orcid.org/0000-0001-7927-

8651

This manuscript was contributed by The Korean Society of Nephrology.
High dietary protein intake may lead to increased intraglomerular pressure and glomerular hyperfiltration, which in the long-term can lead to de novo or aggravating preexisting chronic kidney disease (CKD). Hence, a low protein diet (LPD, 0.6 to $0.8 \mathrm{~g} / \mathrm{kg} / \mathrm{day}$ ) is recommended for the management of CKD. There are evidences that dietary protein restriction mitigate progression of CKD and retard the initiation of dialysis or facilitate incremental dialysis. LPD is also helpful to control metabolic derangements in CKD such as metabolic acidosis and hyperphosphatemia. Recently, a growing body of evidence has emerged on the benefits of plant-dominant low-protein diet (PLADO), which composed of $>50 \%$ plantbased sources. PLADO is considered to be helpful for relieving uremic burden and metabolic complications in CKD compared to animal protein dominant consumption. It may also lead to favorable alterations in the gut microbiome, which can modulate uremic toxin generation along with reducing cardiovascular risk. Alleviation of constipation in PLADO may minimize the risk of hyperkalemia. A balanced and individualized dietary approach for good adherence to LPD utilizing various plant-based sources as patients' preference should be elaborated for the optimal care in CKD. Periodic nutritional assessment under supervision of trained dietitians should be warranted to avoid protein-energy wasting.

Keywords: Renal insufficiency, chronic; Diet, protein-restricted; Glomerular hyperfiltration; Plant-dominant low protein diet; Protein energy wasting

\section{INTRODUCTION}

There is growing concern worldwide regarding the exponential increase in the prevalence of chronic kidney disease (CKD), particularly in Asia and including Korea, which has the highest incidence rate of end-stage renal disease according to United States Renal Data System
(USRDS) data [1]. Balanced nutritional therapy along with appropriate pharmacological interventions are essential aspects of the management of CKD patients for stabilization of kidney function and prevention of other end-organ complications [2]. However, there are still controversies regarding certain dietary strategies, such as controlling the amount and quality of protein intake 
in CKD patients. Furthermore, recommendations for a low protein diet (LPD) may differ across the stages of CKD due to differential risk-to-benefit ratio profiles. This review is focused on the nephron-protective role of LPD in CKD patients and presents a summary of current clinical practice guidelines and supporting evidence for nutritional management regarding the amount of protein intake in patients with CKD.

\section{CURRENT STATUS OF DIETARY PROTEIN INTAKE AND CONCERNS ABOUT KIDNEY HEALTH}

The essential amount of protein intake was originally calculated to compensate for daily obligatory nitrogen loss through protein degradation and nitrogen excretion. The estimated average requirement (EAR) for protein intake in adults was suggested to be 0.46 to 0.66 $\mathrm{g} / \mathrm{kg} /$ day (grams of protein per kilogram of ideal body weight per day), which corresponds to the amount of dietary protein required to avoid negative nitrogen balance [3], while a dietary protein intake as low as 0.46 $\mathrm{g} / \mathrm{kg} /$ day would suffice to avoid negative nitrogen balance if all essential amino acids are provided [4]. The recommended daily allowance for protein intake was estimated as $0.8 \mathrm{~g} / \mathrm{kg} /$ day to meet the requirements of $97 \%$ to $98 \%$ of the population (two standard deviations above the EAR) [5], which has become the upper threshold for LPDs. Although most nutritional guidelines for CKD patients recommend a LPD, there appears to be a significant gap from the actual protein consumption. According to a study based on the National Health and Nutrition Examination Survey (NHANES) between 2001 and 2008, an average American consumed 1.3 to $1.5 \mathrm{~g} / \mathrm{kg}$ of protein per day, and protein intake exceeded $1 \mathrm{~g} / \mathrm{kg} /$ day even in those aged $>75$ years or with advanced renal insufficiency, such as CKD stage 4. Dietary patterns in South Korea have also changed toward consuming larger amounts of protein. A report based on the Korean National Health and Nutrition Examination Survey (KNHANES) indicated estimated protein consumption of $250 \%$ to $300 \%$ of the average required amount in the population between 10 and 64 years old, which is comparable to the NHANES data [6]. The definitions for range of protein intake are summarized in Table $1[7,8]$.
Trends in increasing protein intake have raised concerns about kidney health. There have been several studies regarding the impact of high protein consumption on the kidneys. This issue was first studied in animal experiments, which showed that high-protein meals resulted in dose-dependent increases in glomerular filtration rate (GFR) [9], with estimated maximal GFR increase of nearly $80 \%$. Similar results were demonstrated in human studies showing that a high-protein diet (protein comprising $25 \%$ of calories) increased estimated GFR (eGFR) by $3.8 \mathrm{~mL} / \mathrm{min} / 1.73 \mathrm{~m}^{2}$ compared to a lower protein diet (protein comprising $15 \%$ of calories) after 6 weeks of treatment [10]. Glomerular hyperfiltration ultimately stimulates mesangial cell signaling to increase the level of transforming growth factor- $\beta$ (TGF- $\beta$ ), which subsequently contributes to the progression of kidney fibrosis [11]. Long-standing glomerular hyperfiltration induced by high protein intake may cause kidney damage and decline of kidney function, especially in those with pre-existing CKD. In the 11-year observational Nurses' Health Study, every 10-g increase in protein intake was significantly associated with a worsening in eGFR of $-1.69 \mathrm{~mL} / \mathrm{min} / 1.73 \mathrm{~m}^{2}$ (95\% CI, -2.93 to -0.45 ) among women with mild renal insufficiency (defined as eGFR of 55 to $80 \mathrm{~mL} / \mathrm{min} / 1.73 \mathrm{~m}^{2}$ ) [12].

High dietary protein intake may accelerate apoptosis of podocytes. Protein-rich foods, such as meat cooked at high heat, contain high levels of advanced glycation end products (AGEs) [13], which impairs protein degradation leading to basement membrane thickening and mesangial expansion in glomerulus of diabetic kidney disease [14]. Amino acid and high glucose treatment can lead to podocyte and mesangial cell cycle arrest and apoptosis in vitro experiment. Moreover, the podocyte count was reduced in diabetic mice fed high protein diet [15]. These pathogenic response of AGEs could be mediated with a proinflammatory receptor for AGE (RAGE) presented on glomerular cells [14]. RAGE activated signals culminating in cellular inflammation and death, and inhibition of RAGE attenuated apoptosis and inflammatory cytokine production caused by amino acid and high glucose treatment in podocyte and mesangial cells [15]. The vulnerability of podocytes to AGEs is accentuated in glomerular hypertrophy because a single podocyte must cover a larger surface area [16]. Possible mechanisms of high dietary protein diet on kidney injury was summarized in Fig. 1. 
Table 1. Definitions regarding the range of dietary protein intake in the KDOQI CPG for nutrition in CKD 2020 update and from the ISRNM $[7,8]$

\begin{tabular}{|c|c|c|}
\hline Dietary protein intake range & $\begin{array}{l}\text { Amount of daily protein } \\
\text { intake, g/kg/day }\end{array}$ & Comments \\
\hline Protein free diet & $<0.25$ & Not recommended including CKD patients \\
\hline Very low protein diet (VLPD) & $0.25-0.55$ & $\begin{array}{l}\text { Prescribed with supplementation of essential amino acid or } \\
\text { keto-analogs (EA/KAA). VLPD (0.28-0.43 g/kg/day) with EA/ } \\
\text { KAA meets the protein requirement for non-diabetic CKD } \\
\text { patients in metabolically stable condition. }\end{array}$ \\
\hline Low protein diet (LPD) & & KDOQI CPG recommended LPD for advanced CKD (stage \\
\hline Non-diabetic CKD & $0.55-0.6$ & $3-5)$. If it contains $>50 \%$ high biologic value protein, no \\
\hline Diabetic CKD & $0.6-0.8$ & $\begin{array}{l}\text { supplementation is needed. The recommended amount of } \\
\text { protein intake is slightly higher in CKD with diabetes }\end{array}$ \\
\hline Moderately low protein diet & $0.8-1.0$ & $\begin{array}{l}\text { Usually recommended for adults without but at high risk of } \\
\text { CKD (solitary kidney, diabetes, hypertension and PCKD, etc.) }\end{array}$ \\
\hline Moderate protein diet & $1.0-1.2$ & $\begin{array}{l}\text { Recommanded for patients on maintenance hemodialysis or } \\
\text { peritoneal dialylsis in metabolically stable condition }\end{array}$ \\
\hline Moderately high protein diet & $1.2-1.5$ & $\begin{array}{l}\text { Average actual consumption of protein intake in the reports } \\
\text { analyzing dietary pattern including NHANES or KNHANES }\end{array}$ \\
\hline High to very high protein diet & $>1.5$ & $\begin{array}{l}\text { Possibly considered within certain limited period of time in } \\
\text { acute hypercatabolic state such as AKI, burn or PEW }\end{array}$ \\
\hline
\end{tabular}

KDOQI, Kidney Disease Outcomes Quality Initiative; CPG, Clinical Practice Guideline; CKD, chronic kidney disease; ISRNM, International Society of Renal Nutrition and Metabolism; PCKD, polycystic kidney disease; NHANES, National Health and Nutrition Examination Survey; KNHANES, Korean National Health and Nutrition Examination Survey; AKI, acute kidney injury; PEW, protein energy wasting.

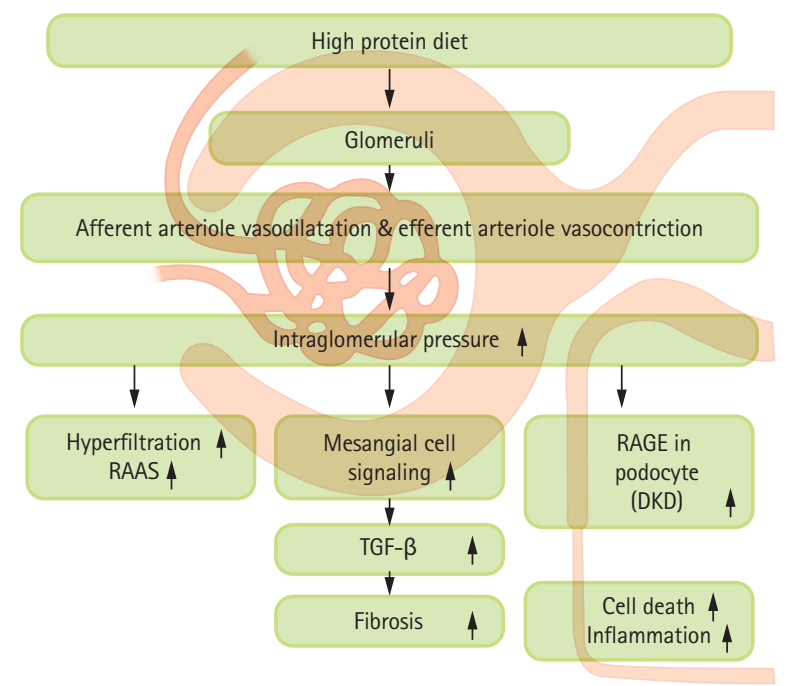

Figure 1. Possible mechanisms of high dietary protein intake on kidney health. High protein diet leads to the dilation of the afferent arteriole and increased glomerular filtration rate, which may lead to damage to kidney structure over time due to glomerular hyperfiltration. RAAS, renin-angiotensin-aldosterone system; TGF- $\beta$, transforming growth factor-beta; RAGE, receptor for advanced glycation end products; DKD, diabetic kidney disease.

\section{BENEFITS OF LOW PROTEIN DIET}

A LPD has many advantages in the management of CKD patients by reducing nitrogen waste products and decreasing kidney workload through lowering intraglomerular pressure, which has a kidney protective effect especially in those with a decreased reservoir in functioning nephrons. LPD also leads to favorable metabolic effects that can preserve kidney function and help to control uremic symptoms.

\section{EFFECTS OF LOW PROTEIN DIET ON PROTEINURIA}

Glomerular hyperfiltration caused by a high protein diet is associated with glomerular structural damage and increased pressure on the remaining glomeruli, which may lead to increased risk of proteinuria. Although the precise pathophysiology has not been elu- 
cidated, high protein intake is involved in renal solute excretion workload and tubular amino acid overload, resulting in vasodilation of the afferent glomerular arterioles. The paracrine factors and mediators associated with glomerular hemodynamics, such as insulin-like growth factor 1, prostanoids, nitric oxide, and the renin-angiotensin-aldosterone system (RAAS), have been suggested to be involved in this response [17]. Moreover, increased proinflammatory cytokine gene expression by a high-protein diet may be associated with structural damage and hyperfiltration by the remaining glomeruli [18]. This consequence of a high-protein diet has been shown clinically to be associated with increased risk of albuminuria, compared to a standard protein intake in several observational studies, even after accounting for the influence of sociodemographic factors, comorbidities, anthropometric factors, health behaviors (e.g., physical activity, energy intake, smoking status), and medication history, although other studies yielded inconsistent data indicating no association or associations only in patients with hypertension and diabetes. In a study with a crossover design among patients with nephrotic syndrome comparing standard versus LPD periods, protein restriction was shown to lead to a up to $20 \%$ reduction in proteinuria in all patients, which supported the beneficial role of LPD on proteinuria even after considering that it was conducted in a small group with a short intervention period (2 weeks) [19]. LPD was also associated with better control of blood pressure, which is closely related to kidney outcome [2o]. In a study among patients with CKD IV and V, a very-LPD supplemented with ketoanaloguess (SVLPD) resulted in significant reductions in blood pressure of about $10 \%(143 \pm 19 / 83 \pm 10$ to $128 \pm 16 / 78 \pm 7 \mathrm{mmHg} ; p$ $<0.001$ ) [21]. The effects of LPD on kidney physiology showed many similarities to those of RAAS inhibition, and an experimental study showed that it had an additive anti-proteinuric effect with RAAS inhibition [17]. A recent review by Koppe and Fouque [17], the authors outlined potential mechanisms of action and additive efficacy of an LPD and RAAS inhibitors in CKD, with a particular emphasis on phosphate levels, uremic toxin production, acid load, and salt intake. Therefore, combined treatment with LPD and the RAAS blockade may be warranted to achieve lower urinary protein levels and to further reduce the risk of CKD progression. Recently, sodium glucose cotransporter-2 (SGLT2) inhibitors have also been shown reno-protection including reduction of albuminuria and attenuation of renal function decline. It is suggested that reno-protective effects of SGLT2 are mediated possibly through glomerular hyperfiltration via the improvement of the tubulo-glomerular feedback, which share the protective mechanisms in LPD and RAAS blockade [22,23]. Future studies are needed to examine whether a similarly synergistic effects would exits if SGLT2 inhibitors are given in combination with LPD and plant-dominant diets [24].

\section{EFFECTS OF LOW PROTEIN DIET ON RETAR- DATION OF CKD PROGRESSION AND DELAY OF DIALYSIS}

As the kidneys are responsible for the excretion of most protein degradation products, there will be accumulation of these byproducts, such as p-cresyl sulfate, indoxyl sulfate, and trimethylamine oxide, in CKD patients [25], which will result in further progressive impairment of kidney function [26]. However, the Modification of Diet in Renal Disease (MDRD) study, the largest controlled trial in CKD patients to date, failed to demonstrate the effectiveness of LPD in retarding CKD progression [27], Instead, it suggested that LPD may have negative effects in the management of CKD. Nevertheless, secondary analysis of the MDRD study with a longer observation period showed that each $0.2 \mathrm{~g} / \mathrm{kg} /$ day decrease in protein intake was associated with a slower decline of GFR by $1.15 \mathrm{~mL} / \mathrm{min} / 1.73 \mathrm{~m}^{2}$ per year, and with a halved risk of kidney failure or death [28]. Moreover, subsequent meta-analyses and systemic reviews also reported similar results. A systemic review analyzing data of non-diabetic CKD patients demonstrated that restricted protein intake significantly reduced the number of patients initiating dialysis treatment by about 32\% [26]. A more recent meta-analysis including seven randomized controlled trials (RCTs) reported significant protective effects of LPD and SVLPD on decrease in eGFR, compared to a normal protein diet [29]. Reduced uremic milieu with SVLPD was also helpful for maintaining urine volume and residual renal function, which enabled implementation of a weekly incremental dialysis program. After 24 months of the program, $40 \%$ of patients were still 
on weekly dialysis treatment, without deterioration of nutritional status, aggravated anemia, or metabolic derangement [30].

The renoprotective effect of LPD may be reinforced in proportion to the extent of protein restriction. A recent RCT showed that SVLPD (0.3 g/kg/day) mitigated kidney function decline and reduced the number of patients requiring renal replacement therapy in comparison with conventional LPD (0.6 g/kg/day) [31]. Supplementation with ketoanaloguess, which can be converted and utilized as essential amino acids, help to maintain protein-energy status without increases in levels of nitrogen waste products with reduced phosphorus and acid load in VLPD along with decreased protein degradation and enhanced protein synthesis [32]. SVLPD was demonstrated to reduce the levels of major uremic toxins, such as indoxyl sulfate, in predialysis CKD patients [33]. In another RCT among patients with GFR 5 to $7 \mathrm{~mL} / \mathrm{min}$, SVLPD even delayed the initiation of dialysis treatment effectively by a mean period of 10.7 months without negative consequences, which provided economic benefits estimated at $€ 21,180$ per patient in the first year [34].

\section{BENEFICIAL EFFECTS OF LOW PROTEIN DIET ON METABOLIC CONSEQUENCES}

\section{Regarding metabolic acidosis}

Metabolic acidosis, a common metabolic consequence of advanced CKD, should be controlled to retard CKD progression and prevent other complications, such as insulin resistance and cardiovascular diseases [35]. As acid is generated during the process of protein degradation, including sulfur-containing amino acids, higher intake of proteins and elevated dietary acid load are associated with a rapid decrease in kidney function [36], and it is independently associated with increased risk of end-stage renal disease in CKD patients [37]. Therefore, LPD, especially if it is predominantly from plant sources (see below), is believed to have favorable effects on metabolic acidosis in CKD patients. Indeed, LPD was reported to ameliorate metabolic acidosis in patients with advanced CKD. In an RCT investigating the effects of diet on serum bicarbonate for 1 year, mean serum bicarbonate level remained $<19 \mathrm{mmol} / \mathrm{L}$ after 1 year of LPD, whereas it increased to the normal level in the
SVLPD group [31]. In another study, the amount of oral bicarbonate replacement to maintain a similar level of serum bicarbonate (or comparable serum total carbon dioxide [38]) was lower in the SVLPD group compared to participants who consumed higher levels of protein [39]. Correcting metabolic acidosis either by dietary modification or by sodium bicarbonate replacement was helpful to retard the decline of kidney function in patients with stage $4 \mathrm{CKD}[40]$.

\section{Regarding hyperphosphatemia}

As protein-rich foods are the main natural source of phosphorus intake ( $1 \mathrm{~g}$ of protein contains about $13 \mathrm{mg}$ of phosphorus) [41], and there is a good correlation between dietary protein and phosphorous intake, LPD could be helpful for controlling hyperphosphatemia in CKD patients, which is a well-known risk factor for cardiovascular disease and bone strength abnormalities [42]. In an RCT in patients with CKD IV and V, dietary protein restriction was shown to lead to declines in serum phosphate levels and calcium-phosphorus product [43]. The efficacy of LPD for lowering serum phosphorus levels also led to reductions in serum levels of parathyroid hormone and fibroblast growth factor 23 [44,45], and better control of markers of mineral bone disorder through dietary protein restriction may be associated with slowing the progression of vascular calcification and improving cardiovascular outcome [46].

\section{Regarding nephrolithiasis}

High-protein diets, especially non-dairy animal protein (poultry, meat, fish, eggs), with low-alkali food is considered to be associated with stone formation in the urinary tract. It is thought to cause negative calcium balance, low urinary $\mathrm{pH}$, and low urinary excretion of citrate, potassium, and magnesium [47]. Especially, animal protein intake increases purine metabolism causing hyperuricosuria, which contributes to both uric acid and calcium nephrolithiasis $[48,49]$. Dietary protein restriction leads to significant decreases in urinary calcium, uric acid, oxalate, and hydroxyproline levels. On the other hand, urinary citrate was reported to increase after adoption of LPD along with decreased urinary excretion of urea [50]. It is possible that there are individual variations that result in differences in the effects of dietary factors on stone formation. High animal protein intake was shown 
to be associated with urinary oxalate excretion in patients with idiopathic calcium nephrolithiasis, whereas no such effect was observed in healthy subjects [51].

\section{IMPORTANCE OF SOURCE OF PROTEIN IN- TAKE (PLANT VS. ANIMAL PROTEIN)}

In addition to the amount of protein intake, the possibility of different effects according to the source of dietary protein has attracted interest. Consumption of animal protein, especially processed red meat, is highly associated with the incidence and progression of CKD. The Atherosclerosis Risk in Communities Study (ARIC), a prospective cohort study as an observation of United States community population without diabetes and cardiovascular disease in eGFR $>60 \mathrm{~mL} / \mathrm{min} / 1.73 \mathrm{~m}^{2}$ with a median follow-up of 23 years, showed an increased risk of the incidence of CKD among those who consumed the highest quintile of red/processed meat compared to those who consumed the least [52]. Beneficial association of plant-based protein intake with CKD incidence was evident in healthy plant-based diet consuming whole grain, fruit, vegetable, nuts and legumes rather than less-healthy plant-based diet with refined grain, potatoes, fruit juice and sugar-sweetened beverages [53]. Similar results were demonstrated in a study performed in Asia; the Singapore Chinese Health Study, which showed a strong association of red meat consumption with ESRD risk in a dose-dependent manner [54]. Renoprotective effect of plant-based protein consumption was associated lower mortality in CKD patients [55].

Although detailed mechanism for the different effect regarding the sources dietary protein, it was demonstrated in a clinical study that higher glomerular hyperfiltration was observed in population with more meat and less vegetable protein intake [56]. This result was supported with another longitudinal observational study, the Nurses' Health Study with 11-year follow-up periods upon 3,328 population, which demonstrated that the highest quartile of animal fat and two or more servings of red meat per week were directly associated with microalbuminuria [57]. Animal protein diet is also believed to cause an imbalance in the composition of the gut microbiome [58] resulting in the production of greater amounts of ammonia and sulfur-based materi- als with a proinflammatory profile, and thus lead to increases in inflammatory cytokines and oxidative stress [59,6o]. A longitudinal controlled trial among patients with diabetic nephropathy demonstrated that replacing half of animal protein intake with soy protein consumption for 4 years decreased the degree of proteinuria and urinary creatinine [61] along with improvement of markers of metabolic syndrome, which is related to increased risk of CKD [62].

Moreover, many studies have suggested that plant protein is more helpful for controlling metabolic acidosis. Plant-based protein contains higher levels of glutamate, an anionic amino acid that consumes hydrogen ions in metabolism, resulting in maintenance of neutral $\mathrm{pH}$. Plant foods also contain higher levels of anionic potassium salts, which also result in a decrease in levels of hydrogen ions [63]. The Chronic Renal Insufficiency Cohort Study demonstrated that consumption of a greater proportion of plant protein was associated with higher bicarbonate levels [45]. As oral bioavailability of phosphorus is higher in animal protein, compared to plantbased protein, whose phosphorus in the form of phytate is less bioavailable in human gut, more animal protein consumption may also be harmful for controlling hyperphosphatemia in CKD patients [64].

Based on the results of many studies on the favorable effect of plant-based protein intake, there is a movement to recommend a plant-dominant low-protein diet (PLADO) in CKD patients $[7,60,65]$. It is defined as a diet of dietary protein intake of 0.6 to $0.8 \mathrm{~g} / \mathrm{kg} /$ day with at least 50\% plant-based sources, which should be whole, unrefined, and unprocessed foods. Other features of PLADO include low sodium intake less than 3 to $4 \mathrm{~g} /$ day and high dietary fiber of at least 25 to $30 \mathrm{~g} /$ day under ensuring adequate energy intake (30 to $35 \mathrm{Cal} / \mathrm{kg} /$ day) [6o]. Although introduction of PLADO regimen in CKD patients is supposed to yield various beneficial effect as stated above, there are also several concerns. Most of animal protein are complete proteins, which provide all essential amino acid supplied necessarily from foods.

It is important to note that plant proteins are often considered be lack some of essential amino acids, and therefore are usually categorized as having a low biological value as compared to the so-called "high biologic value" (HBV) proteins that are mostly of animal origin, in which more essential amino acids are bioavailable 
Table 2. Composition of PLADO and its benefits and challenges [60]

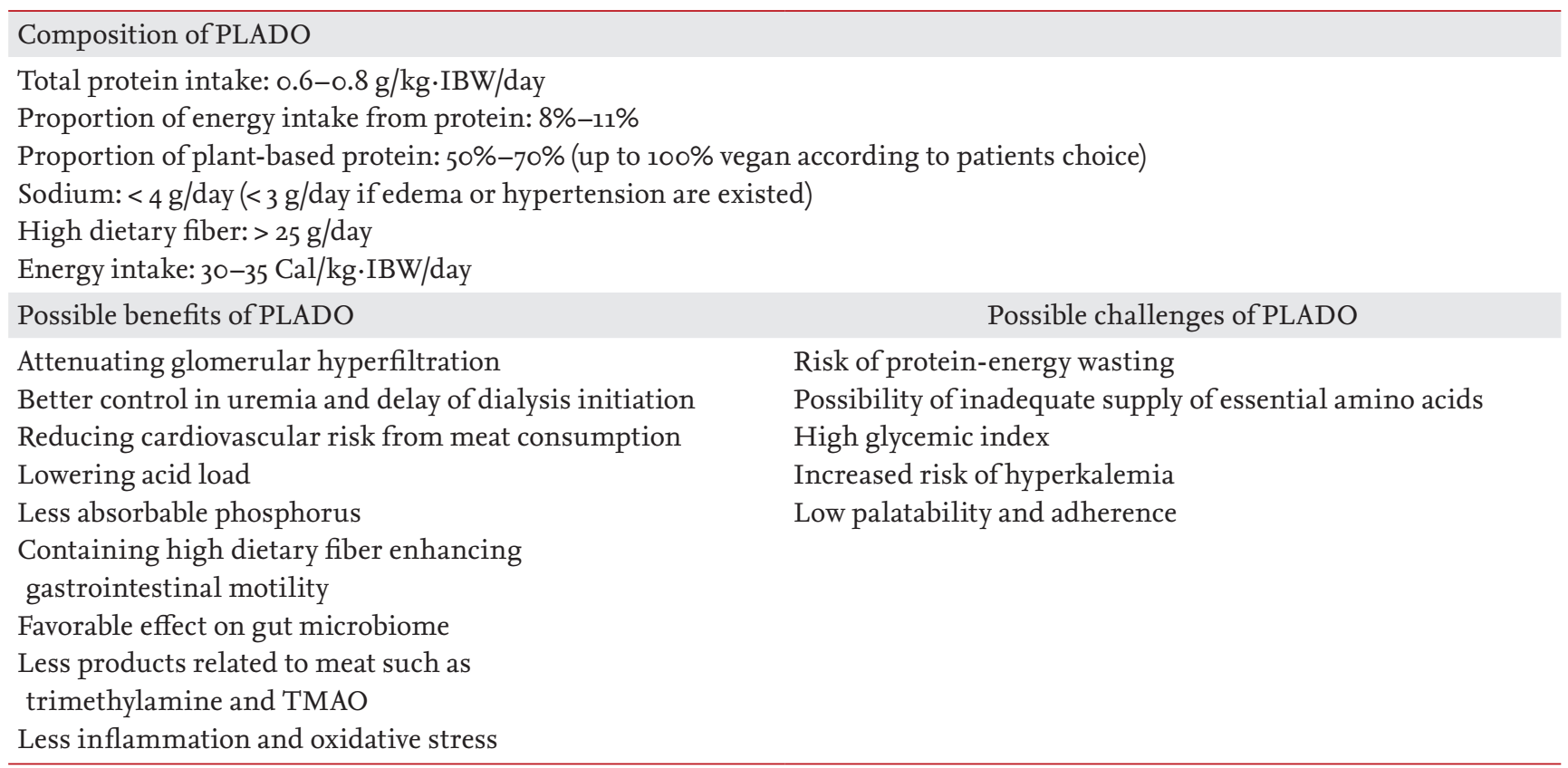

PLADO, plant-dominant low protein diet; IBM, ideal body weight; TMAO, trimethylamine N-oxide.

and absorbable via human gut. However, despite the traditionally lower HBV ranking of plant-based protein, they do not have significantly lower "protein digestibility-corrected amino-acid score" (PDCAAS), which is the preferred method for measuring protein quality, compared to animal-based proteins. Indeed, clinical studies using near total plant-based diet or exclusively plantbased diet in CKD patients did not show any nutritional deficits [66-68]. Hence, careful monitoring about the adequacy for quantity and quality through utilizing a variety of foods may enable to use plant-based diet in CKD patients without adverse effect. A recent United States national study showed that higher HBV protein was associated with poor outcomes in those with CKD [69].

Another concern with plant-based diet is about the risk of hyperkalemia. However, dietary potassium explained only about $2 \%$ of the variance in quarterly mean pre-dialysis serum potassium [70]. Moreover, the top five sources of potassium were beef, chicken, Mexican food, hamburgers and legumes [71]. Indeed, a high-fiber diet may enhance bowel motility and likely prevent more absorption of potassium from foods. Alkali supply with plant-based dietary sources may also lower the risk of hyperkalemia [72,73]. Indeed a recent study sug- gested that lowering dietary potassium was associated with worse mortality in patients with CKD undergoing dialysis [74]. Benefits and challenges of PLADO are summarized in Table 2. Close monitoring for the adherence to intake of proper amount of calori, protein, salt and fiber, and flexible application of protein sources and food types according to the preference of patients may be helpful to convey the better beneficial impact of PLADO regimen on kidney health.

\section{RISK OF PROTEIN ENERGY WASTING \& MONI- TORING}

The hypercatabolic state induced by uremia, anorexia due to accumulation of anorectics, inflammation from systemic conditions, and underlying autoimmune conditions as etiologies for CKD have been suggested to be related to a high prevalence of protein energy wasting (PEW) [75] in CKD patients, associated with low muscle mass and increased mortality [76]. As malnutrition is the main risk factor for PEW, restriction of protein intake raised concerns about the possibility of aggravating PEW in CKD patients, and decreased body mass 
index was shown to be associated with higher mortality of ESRD patients treated with dialysis [77,78]. Analysis of body composition measurements conducted in the MDRD study showed decreases in body weight, arm muscle area, and urine creatinine excretion in the lowand very-low protein intake groups, compared to the control diet. However, caloric intake was also decreased in the protein restriction group, and the averages of most anthropometric and biochemical indices for nutritional status remained within the normal ranges [79].

Another study investigating the effects of SVLPD on body composition among CKD V patients showed slight decreases in lean body mass during the first 3 months after the diet intervention. However, it gradually increased thereafter, and remained stable at 12 and 24 months, suggesting that SVLPD coupled with adequate caloric intake is nutritionally safe for long periods
[80]. A meta-analysis of 14 studies evaluated the effects of LPD on body composition in CKD patients, and it demonstrated that there were no major changes in body composition over time in CKD patients with LPD [81]. However, as protein and energy requirements should be varied according to clinical conditions and across disease severities, it is essential to monitor actual dietary intake regularly and to assess nutritional status carefully in the implementation of LPD $[82,83]$. Dietary intake can be evaluated with dietary recalls, interviews, and food frequency questionnaires, and the amount of actual protein intake can be verified with urinary nitrogen appearance (UNA). However, protein intake can be overestimated by UNA-based calculation if patients are in a hypercatabolic state, including malnutrition, inflammatory conditions, postoperative period, and burn injury. So, other tools for dietary assessment should be adopted

Table 3. Potential benefit of low protein diet on kidney health

Improvement of proteinuria

Avoid glomerular hyperfiltration and decreased load on remaining nephron $[18,19]$

Synergistic mitigation with RAAS inhibition [17]

Retardation of CKD progression

Although there was a slight drop of GFR in first several months [27], eGFR deterioration was attenuated with LPD [26,28,29].

Delayed dialysis and adaptation of incremental dialysis

Decreased level of uremia [29,31]

Reduced production of waste products in protein degradation metabolism $[28,31]$

Alleviating metabolic acidosis

Hydrogen ion generation decreased proportionally to the amount of daily protein intake [31,35,36]. Intake of plant-based protein intake contributes to better control of the acid-base balance [63]

Attenuating the progression of mineral bone disorder

Lower phosphorus content of LPD helps to better control of hyperphosphatemia along with decreased level of parathyroid hormone and FGF-23 [44,45]

Reduced risk of nephrolithiasis

Decreases in urinary calcium, uric acid, oxalate, and hydroxyproline levels, whereas increase of urinary citrate [47,49]

Better control of hypertension

Along with reduced intake of sodium [21]

Favorable impacts on the gut microbiome

Lower generation of uremic toxins such as p-cresol sulfate, indoxil sulfate, and TMAO [35,88-91]

Miscellaneous

LPD may improve insulin resistance [92]

LPD may attenuate oxidative stress and inflammation $[15,41]$

RAAS, renin-angiotensin-aldosterone system; CKD, chronic kidney disease; GFR, glomerular filtration rate; LPD, low protein diet; FGF-23, fibrous growth factor-23; TMAO, trimethylamine N-oxide. 
in those conditions. [84]. In addition, dialysis treatment stimulates protein catabolism [85]. Whole-body skeletal muscle metabolism appears to increase, which can lead to the net loss of muscle protein during hemodialysis treatment [86]. The guidelines recommend higher dietary protein intake in ESRD patients undergoing dialysis treatment (1.2 to $1.4 \mathrm{~g} / \mathrm{kg} /$ day), compared to the pre-dialysis period, to avoid aggravation of $\mathrm{PEW}[87]$. Education for close self-monitoring to avoid malnutrition and consistent counselling by CKD-specialized dietitian, who provides pragmatic tools and comprehensible dietary information and skills are necessary to exert the role of LPD on kidney health without risk of PEW.

\section{CONCLUSIONS}

In the management of patients with CKD, the beneficial effects of plant-dominant LPD to avoid glomerular hyperfiltration and mitigate accumulation of protein waste products are thought to be useful for better control of uremic symptoms and metabolic complications, facilitating delay in the initiation of dialysis treatment (Table 3) [15,17-19,21,26-29,31,35,36,41,44,45,47,49,63,88-92]. However, concerns regarding PEW have hindered the widespread adoption of these strategies by clinicians. Implementation of LPD as a dietary regimen should be recommended along with close monitoring and precise regular assessment of nutritional status. Multidirectional approaches, including dietary approaches, should be considered to ensure the best outcome for CKD patients.

\section{Conflict of interest}

No potential conflict of interest relevant to this article was reported.

\section{REFERENCES}

1. Collins AJ, Foley RN, Chavers B, et al. US renal data system 2013 annual data report. Am J Kidney Dis 2014;63(1 Suppl):A7.

2. Kim SM, Jung JY. Nutritional management in patients with chronic kidney disease. Korean J Intern Med 2020;35:1279-1290.
3. Wolfe RR, Cifelli AM, Kostas G, Kim IY. Optimizing protein intake in adults: interpretation and application of the recommended dietary allowance compared with the acceptable macronutrient distribution range. Adv Nutr 2017;8:266-275.

4. Kovesdy CP, Kopple JD, Kalantar-Zadeh K. Management of protein-energy wasting in non-dialysis-dependent chronic kidney disease: reconciling low protein intake with nutritional therapy. Am J Clin Nutr 2013;97:1163-1177.

5. Trumbo P, Schlicker S, Yates AA, Poos M; Food and Nutrition Board of the Institute of Medicine, The National Academies. Dietary reference intakes for energy, carbohydrate, fiber, fat, fatty acids, cholesterol, protein and amino acids. J Am Diet Assoc 2002;102:1621-1630.

6. Chang SO. Dietary reference intakes for protein: protein requirement and estimation method, AMDR (Amount of Macronutrient Distribution Range), for protein. Korean J Nutr 2011;44:338-343.

7. Kistler BM, Moore LW, Benner D, et al. The International Society of Renal Nutrition and Metabolism commentary on the National Kidney Foundation and Academy of Nutrition and Dietetics KDOQI clinical practice guideline for nutrition in chronic kidney disease. J Ren Nutr 2021;31:116-120.

8. Ikizler TA, Burrowes JD, Byham-Gray LD, et al. KDOQI clinical practice guideline for nutrition in CKD: 2020 update. Am J Kidney Dis 2020;76(3 Suppl 1):S1-S1O7.

9. Moustgaard J. Variation of the renal function in normal and unilaterally nephrectomized dogs. Am J Vet Res 1947;8:301-306.

10. Juraschek SP, Appel LJ, Anderson CA, Miller ER 3rd. Effect of a high-protein diet on kidney function in healthy adults: results from the OmniHeart trial. Am J Kidney Dis 2013;61:547-554.

11. Kitada M, Ogura Y, Monno I, Koya D. A low-protein diet for diabetic kidney disease: its effect and molecular mechanism, an approach from animal studies. Nutrients 2018;10:544.

12. Knight EL, Stampfer MJ, Hankinson SE, Spiegelman D, Curhan GC. The impact of protein intake on renal function decline in women with normal renal function or mild renal insufficiency. Ann Intern Med 2003;138:460467.

13. Goldberg T, Cai W, Peppa M, et al. Advanced glycoxidation end products in commonly consumed foods. J Am Diet Assoc 2004;104:1287-1291. 
14. Yamagishi S, Matsui T. Advanced glycation end products, oxidative stress and diabetic nephropathy. Oxid Med Cell Longev 2010;3:101-108.

15. Meek RL, LeBoeuf RC, Saha SA, et al. Glomerular cell death and inflammation with high-protein diet and diabetes. Nephrol Dial Transplant 2013;28:1711-1720.

16. Kramer H. Diet and chronic kidney disease. Adv Nutr 2019;10(Suppl_4):S367-S379.

17. Koppe L, Fouque D. The role for protein restriction in addition to renin-angiotensin-aldosterone system inhibitors in the management of CKD. Am J Kidney Dis 2019;73:248-257.

18. Tovar-Palacio C, Tovar AR, Torres N, et al. Proinflammatory gene expression and renal lipogenesis are modulated by dietary protein content in obese Zucker fa/fa rats. Am J Physiol Renal Physiol 2011;300:F263-E271.

19. Kaysen GA, Gambertoglio J, Jimenez I, Jones H, Hutchison FN. Effect of dietary protein intake on albumin homeostasis in nephrotic patients. Kidney Int 1986;29:572577.

20. Son HE, Ryu JY, Go S, et al. Association of ambulatory blood pressure monitoring with renal outcome in patients with chronic kidney disease. Kidney Res Clin Pract 2020;39:70-80.

21. Bellizzi V, Di Iorio BR, De Nicola L, et al. Very low protein diet supplemented with ketoanalogs improves blood pressure control in chronic kidney disease. Kidney Int 2007;71:245-251.

22. Fioretto P, Zambon A, Rossato M, Busetto L, Vettor R. SGLT2 inhibitors and the diabetic kidney. Diabetes Care 2016;39 Suppl 2:S165-S171.

23. Cherney DZ, Perkins BA, Soleymanlou N, et al. Renal hemodynamic effect of sodium-glucose cotransporter 2 inhibition in patients with type 1 diabetes mellitus. Circulation 2014;129:587-597.

24. Kalantar-Zadeh KJT, Nitsch D, Neuen B, Perkovic V. Preserving kidney function in people with chronic kidney disease (Invited Seminar). Lancet. 2021 In Press.

25. Park JS, Choi HI, Bae EH, Ma SK, Kim SW. Paricalcitol attenuates indoxyl sulfate-induced apoptosis through the inhibition of MAPK, Akt, and NF-kB activation in HK-2 cells. Korean J Intern Med 2019;34:146-155.

26. Fouque D, Laville M. Low protein diets for chronic kidney disease in non diabetic adults. Cochrane Database Syst Rev 2009;(3):CDoo1892.

27. Klahr S, Levey AS, Beck GJ, et al. The effects of dietary protein restriction and blood-pressure control on the progression of chronic renal disease. Modification of Diet in Renal Disease Study Group. N Engl J Med 1994;330:877884.

28. Levey AS, Greene T, Beck GJ, et al. Dietary protein restriction and the progression of chronic renal disease: what have all of the results of the MDRD study shown? Modification of Diet in Renal Disease Study group. J Am Soc Nephrol 1999;10:2426-2439.

29. Jiang Z, Zhang X, Yang L, Li Z, Qin W. Effect of restricted protein diet supplemented with keto analogues in chronic kidney disease: a systematic review and meta-analysis. Int Urol Nephrol 2016;48:409-418.

30. Caria S, Cupisti A, Sau G, Bolasco P. The incremental treatment of ESRD: a low-protein diet combined with weekly hemodialysis may be beneficial for selected patients. BMC Nephrol 2014;15:172.

31. Garneata L, Stancu A, Dragomir D, Stefan G, Mircescu G. Ketoanalogue-supplemented vegetarian very low-protein diet and CKD progression. J Am Soc Nephrol 2016;27:2164-2176.

32. Shah AP, Kalantar-Zadeh K, Kopple JD. Is there a role for ketoacid supplements in the management of CKD? Am J Kidney Dis 2015;65:659-673.

33. Marzocco S, Dal Piaz F, Di Micco L, et al. Very low protein diet reduces indoxyl sulfate levels in chronic kidney disease. Blood Purif 2013;35:196-201.

34. Scalone L, Borghetti F, Brunori G, et al. Cost-benefit analysis of supplemented very low-protein diet versus dialysis in elderly CKD5 patients. Nephrol Dial Transplant 2010;25:907-13.

35. Kalantar-Zadeh K, Fouque D. Nutritional management of chronic kidney disease. N Engl J Med 2017;377:1765-1776.

36. Scialla JJ, Appel LJ, Astor BC, et al. Estimated net endogenous acid production and serum bicarbonate in African Americans with chronic kidney disease. Clin J Am Soc Nephrol 2011;6:1526-1532.

37. Banerjee T, Crews DC, Wesson DE, et al. High dietary acid load predicts ESRD among adults with CKD. J Am Soc Nephrol 2015;26:1693-1700.

38. Hirai K, Minato S, Kaneko S, et al. Approximation of bicarbonate concentration using serum total carbon dioxide concentration in patients with non-dialysis chronic kidney disease. Kidney Res Clin Pract 2019;38:326-335.

39. Di Iorio BR, Di Micco L, Marzocco S, et al. Very low-protein diet (VLPD) reduces metabolic acidosis in subjects 
with chronic kidney disease: the "nutritional light signal" of the renal acid load. Nutrients 2017;9:69.

40. Gaggl M, Sliber C, Sunder-Plassmann G. Effect of oral alkali supplementation on progression of chronic kidney disease. Curr Hypertens Rev 2014;10:112-120.

41. Fouque D, Aparicio M. Eleven reasons to control the protein intake of patients with chronic kidney disease. Nat Clin Pract Nephrol 2007;3:383-392.

42. Cupisti A, Kalantar-Zadeh K. Management of natural and added dietary phosphorus burden in kidney disease. Semin Nephrol 2013;33:180-190.

43. Mircescu G, Garneata L, Stancu SH, Capusa C. Effects of a supplemented hypoproteic diet in chronic kidney disease. J Ren Nutr 2007;17:179-188.

44. Di Iorio B, Di Micco L, Torraca S, et al. Acute effects of very-low-protein diet on $\mathrm{FGF}_{23}$ levels: a randomized study. Clin J Am Soc Nephrol 2012;7:581-587.

45. Scialla JJ, Appel LJ, Wolf M, et al. Plant protein intake is associated with fibroblast growth factor 23 and serum bicarbonate levels in patients with chronic kidney disease: the Chronic Renal Insufficiency Cohort study. J Ren Nutr 2012;22:379-388.

46. Fouque D, Horne R, Cozzolino M, Kalantar-Zadeh K. Balancing nutrition and serum phosphorus in maintenance dialysis. Am J Kidney Dis 2014;64:143-150.

47. Ferraro PM, Bargagli M, Trinchieri A, Gambaro G. Risk of kidney stones: influence of dietary factors, dietary patterns, and vegetarian-vegan diets. Nutrients 2020;12:779.

48. Park JH, Jo YI, Lee JH. Renal effects of uric acid: hyperuricemia and hypouricemia. Korean J Intern Med 2020;35:1291-1304.

49. Choi HK, Atkinson K, Karlson EW, Willett W, Curhan G. Purine-rich foods, dairy and protein intake, and the risk of gout in men. N Engl J Med 2004;350:1093-1103.

50. Giannini S, Nobile M, Sartori L, et al. Acute effects of moderate dietary protein restriction in patients with idiopathic hypercalciuria and calcium nephrolithiasis. Am J Clin Nutr 1999;69:267-271.

51. Nguyen QV, Kalin A, Drouve U, Casez JP, Jaeger P. Sensitivity to meat protein intake and hyperoxaluria in idiopathic calcium stone formers. Kidney Int 2001;59:22732281.

52. Haring B, Selvin E, Liang M, et al. Dietary protein sources and risk for incident chronic kidney disease: results from the Atherosclerosis Risk in Communities (ARIC) study. J Ren Nutr 2017;27:233-242.
53. Kim H, Caulfield LE, Garcia-Larsen V, et al. Plant-based diets and incident CKD and kidney function. Clin J Am Soc Nephrol 2019;14:682-691.

54. Lew QJ, Jafar TH, Koh HW, et al. Red meat intake and risk of ESRD. J Am Soc Nephrol 2017;28:304-312.

55. Chen X, Wei G, Jalili T, et al. The associations of plant protein intake with all-cause mortality in CKD. Am J Kidney Dis 2016;67:423-430.

56. Kontessis P, Jones S, Dodds R, et al. Renal, metabolic and hormonal responses to ingestion of animal and vegetable proteins. Kidney Int 1990;38:136-144.

57. Lin J, Hu FB, Curhan GC. Associations of diet with albuminuria and kidney function decline. Clin J Am Soc Nephrol 2010;5:836-843.

58. Kim SM, Song IH. The clinical impact of gut microbiota in chronic kidney disease. Korean J Intern Med 2020;35:1305-1316.

59. Ko GJ, Rhee CM, Kalantar-Zadeh K, Joshi S. The effects of high-protein diets on kidney health and longevity. J Am Soc Nephrol 2020;31:1667-1679.

6o. Kalantar-Zadeh K, Joshi S, Schlueter R, et al. Plant-dominant low-protein diet for conservative management of chronic kidney disease. Nutrients 2020;12:1931.

61. Azadbakht L, Atabak S, Esmaillzadeh A. Soy protein intake, cardiorenal indices, and C-reactive protein in type 2 diabetes with nephropathy: a longitudinal randomized clinical trial. Diabetes Care 2008;31:648-654.

62. Park S, Lee S, Kim Y, et al. Reduced risk for chronic kidney disease after recovery from metabolic syndrome: a nationwide population-based study. Kidney Res Clin Pract 2020;39:180-191.

63. Snelson M, Clarke RE, Coughlan MT. Stirring the pot: can dietary modification alleviate the burden of CKD? Nutrients 2017;9:265.

64. Kovesdy CP, Kalantar-Zadeh K. Back to the future: restricted protein intake for conservative management of $\mathrm{CKD}$, triple goals of renoprotection, uremia mitigation, and nutritional health. Int Urol Nephrol 2016;48:725-729.

65. Joshi S, McMacken M, Kalantar-Zadeh K. Plant-based diets for kidney disease: a guide for clinicians. Am J Kidney Dis 2021;77:287-296.

66. Joshi S, Shah S, Kalantar-Zadeh K. Adequacy of plantbased proteins in chronic kidney disease. J Ren Nutr 2019;29:112-117.

67. Barsotti G, Morelli E, Cupisti A, Meola M, Dani L, Giovannetti S. A low-nitrogen low-phosphorus Vegan diet for 
patients with chronic renal failure. Nephron 1996;74:390394.

68. Soroka N, Silverberg DS, Greemland M, et al. Comparison of a vegetable-based (soya) and an animal-based low-protein diet in predialysis chronic renal failure patients. Nephron 1998;79:173-180.

69. Narasaki Y, Okuda Y, Moore LW, et al. Dietary protein intake, kidney function, and survival in a nationally representative cohort. Am J Clin Nutr 2021 Mar 19 [Epub]. https://doi.org/10.1093/ajcn/nqabo11.

70. Noori N, Kalantar-Zadeh K, Kovesdy CP, et al. Dietary potassium intake and mortality in long-term hemodialysis patients. Am J Kidney Dis 2010;56:338-347.

71. St-Jules DE, Goldfarb DS, Sevick MA. Nutrient non-equivalence: does restricting high-potassium plant foods help to prevent hyperkalemia in hemodialysis patients? J Ren Nutr 2016;26:282-287.

72. Xu H, Huang X, Riserus U, et al. Dietary fiber, kidney function, inflammation, and mortality risk. Clin J Am Soc Nephrol 2014;9:2104-2110.

73. Kalantar-Zadeh K, Ikizler TA. Let them eat during dialysis: an overlooked opportunity to improve outcomes in maintenance hemodialysis patients. J Ren Nutr 2013;23:157-163.

74. Narasaki Y, Okuda Y, Kalantar SS, et al. Dietary potassium intake and mortality in a prospective hemodialysis cohort. J Ren Nutr 2021;31:411-420.

75. Hanna RM, Ghobry L, Wassef O, Rhee CM, Kalantar-Zadeh K. A practical approach to nutrition, protein-energy wasting, sarcopenia, and cachexia in patients with chronic kidney disease. Blood Purif 2020;49:202-211.

76. Kim JK, Kim SG, Oh JE, et al. Impact of sarcopenia on long-term mortality and cardiovascular events in patients undergoing hemodialysis. Korean J Intern Med 2019;34:599-607.

77. Hwang SD, Lee JH, Jhee JH, Song JH, Kim JK, Lee SW. Impact of body mass index on survival in patients undergoing peritoneal dialysis: analysis of data from the Insan Memorial End-Stage Renal Disease Registry of Korea (1985-2014). Kidney Res Clin Pract 2019;38:239-249.

78. Kim S, Jeong JC, Ahn SY, Doh K, Jin DC, Na KY. Time-varying effects of body mass index on mortality among hemodialysis patients: results from a nationwide Korean registry. Kidney Res Clin Pract 2019;38:90-99.

79. Kopple JD, Levey AS, Greene T, et al. Effect of dietary pro- tein restriction on nutritional status in the Modification of Diet in Renal Disease Study. Kidney Int 1997;52:778-791.

8o. Chauveau P, Vendrely B, El Haggan W, et al. Body composition of patients on a very low-protein diet: a two-year survey with DEXA. J Ren Nutr 2003;13:282-287.

81. Eyre S, Attman PO. Protein restriction and body composition in renal disease. J Ren Nutr 2008;18:167-186.

82. Kalantar-Zadeh K, Kovesdy CP, Bross R, et al. Design and development of a dialysis food frequency questionnaire. $J$ Ren Nutr 2011;21:257-262.

83. Kalantar-Zadeh K, Tortorici AR, Chen JL, et al. Dietary restrictions in dialysis patients: is there anything left to eat? Semin Dial 2015;28:159-168.

84. Ko GJ, Obi Y, Tortorici AR, Kalantar-Zadeh K. Dietary protein intake and chronic kidney disease. Curr Opin Clin Nutr Metab Care 2017;20:77-85.

85. Kalantar-Zadeh K, Cano NJ, Budde K, et al. Diets and enteral supplements for improving outcomes in chronic kidney disease. Nat Rev Nephrol 2011;7:369-384.

86. Obi Y, Qader H, Kovesdy CP, Kalantar-Zadeh K. Latest consensus and update on protein-energy wasting in chronic kidney disease. Curr Opin Clin Nutr Metab Care 2015;18:254-262.

87. Levin A, Stevens PE. Summary of KDIGO 2012 CKD guideline: behind the scenes, need for guidance, and a framework for moving forward. Kidney Int 2014;85:49-61.

88. Ticinesi A, Nouvenne A, Chiussi G, Castaldo G, Guerra A, Meschi T. Calcium oxalate nephrolithiasis and gut microbiota: not just a gut-kidney axis: a nutritional perspective. Nutrients 2020;12:548.

89. Lai S, Molfino A, Testorio M, et al. Effect of low-protein diet and inulin on microbiota and clinical parameters in patients with chronic kidney disease. Nutrients 2019;11:3006.

90. Kalantar-Zadeh K, Moore LW. Does kidney longevity mean healthy vegan food and less meat or is any low-protein diet good enough? J Ren Nutr 2019;29:79-81.

91. Pignanelli M, Bogiatzi C, Gloor G, et al. Moderate renal impairment and toxic metabolites produced by the intestinal microbiome: dietary implications. J Ren Nutr 2019;29:55-64.

92. Rigalleau V, Blanchetier V, Combe C, et al. A low-protein diet improves insulin sensitivity of endogenous glucose production in predialytic uremic patients. Am J Clin Nutr 1997;65:1512-1516. 